\title{
FIGHTING SWAYING IMBALANCES OF POWERS: THE TRANSFORMATION OF SPIRITUAL FREEDOM IN TANG TALES INTO INDIVIDUAL FREEDOM IN HOU HSIAO-HSIEN'S THE ASSASSIN
}

\author{
FRANK KRAUSHAAR
}

\begin{abstract}
The appearance of Hou Hsiao-hsien's 侯孝賢 film The Assassin in 2015 and its distinction the same year with the Best Director's award at the film festival in Cannes has launched an avalanche of confused and confusing reviews in print-media and on the internet. This partly may have been due to the gap between expectations the film's attribution to the wuxia genre generated in the public and what actually Hou expects from his audience. Despite an unmistakable historical contextualisation at the heart of power-struggling between the Tang imperial court and the ruling house of Weibo, a state that manages to assert its de facto independence behind a diaphanous diplomatic veil of loyalty, the story of the young female assassin Nie Yinniang develops into a sphere of its own, which seems to extend beyond the confines of history and strongly suggests a freedom unspeakable within the intellectual parameter of Tang. This paper traces back the film's narrative based on Tang dynasty tales and its cinematic language, and arrives at an interpretation related to contemporary social and political topics such as the female/male body and violence. It also touches upon the cross-strait relations' issues and the "Western" idea of freedom expressed in an apparently traditional Chinese narrative context.
\end{abstract}

Keywords: Hou Hsiao-hsien; The Assassin; Tang chuanqi; Taiwan cinema; gender; freedom

Although today the chuanqi “"Nie Yinniang” 聶隱娘 has been transmitted to the wider Chinese-reading public in the collection of Tang tales compiled by Wang Bijiang 汪辟 彊 in 1936 which contains many of the early literary fiction classics from late medieval China, the text itself can hardly be called a classic in the proper sense. Rarely mentioned by Western sinologists and so far outside the focus of traditional and modern critics from

1 The term chuanqi 傳奇 is historically complex. Here, it refers to a new genre of urban prose that arose in the eighth and ninth centuries in the Tang capital and other major centres of commerce and bureaucracy. Although the authors of these stories refer, or pretend to refer, to factual events and real personalities, the intervention of "strange" ( $q i$ 奇) beings or supernatural powers is the most crucial factor in the development of the storyline. Thus, interaction between narrative and fictional elements seems to be a defining element of the genre. However, modern twentieth-century literary critics accentuate the fictional nature of this prose type and its innovative potential. 
East Asia, “Nie Yinniang” by Pei Xing 裴鋓 also indirectly questions the general preoccupation with romance as a fictive prism of society's desires that seems to be commonplace in the modern perception of chuanqi. With a single exception, the Indiana Companion to Traditional Chinese Literature lists only amorous stories among the "notably influential" chuanqi and notes that in general "sympathy lies with young and aspiring officials or with those who have withdrawn from the official life" (Nienhauser 1986: 356). In fact, withdrawal from "the human world", or from any form of social engagement, is a motif so popular in Chinese traditional literature that even the female hero in Pei Xing's tale ultimately withdraws from the human realm. On the other hand, the figure of the young female assassin, of which Nie Yinniang is the literary archetype, became popular again in the so-called women's fiction (nüzi xiaoshuo 女子小說) of the early twentieth century as a symbol of modernist radicalism. In this context, the female assassin clearly stands for political engagement in a violent sense, not for withdrawal from the human world (Tsu 2008: 167-195).

However, the fact that Pei Xing chose to depict a young woman as the protagonist in a scenario that would otherwise be dominated by men without indulging in her erotic charms contributes greatly to the exceptional nature of the tale. Stephen Owen in his essay "Romance" states: "These Tang stories [of romance] do not represent the social facts of the demimonde; they represent the culture of the demimonde embodied in fictions that are motivated by its deepest concerns" (Owen 1996: 133). If we accept that romance in the elite society of late-eighth-century Chang'an was understood as a metaphor for the "deepest concerns" of society, then the meaning that unfolds in the story of the female assassin Nie Yinniang is likely to concern unspoken thoughts, fantasies, and longings that linger under the surface of language as a means of social communication.

It seems that director Hou Hsiao-hsien and screenwriter Chu Tien-wen approached "Nie Yinniang" and the film's other literary source, "The Story of Hong Xian" (Hong Xian zhuan 紅線傳), attributed to Yuan Jiao 袁郊 (ninth century AD), from the angle of contemporary literary criticism, putting the character of the female assassin on the same level as the much more famous "fragile scholar" figure. ${ }^{2}$ Scholars widely agree that the experimental nature and allusive breadth of many Tang chuanqi in general not only stimulated the contemporary reader to whom they were first directed to reflect upon the experience of their own age in a more pluralistic manner but have since then never ceased to have an impact on the literary production of later ages. Because romance is highly valued in both the traditional Chinese view and the modern perception of the genre, The Assassin meant a significant shift in the cultural perception of literary tradition in the contemporary Sinophone world.

\section{The literary archetype}

Since Sima Qian's “Biographical Sketches of Assassin-Retainers” (Cike liezhuan 刺 客列傳) in chapter 86 of the Shiji, the narrative material subsumed under the topic of

2 For a comparison of the "fragile scholar", a concept invented by cultural anthropologist Song Geng to designate the object of a study published in 2004, with the female assassin, see further below. 
assassins, in as far as its protagonists mostly linger between open violation of the law and propriety and secretly legitimate personal motives, also evokes associations with the demimonde. Their fortunes are similar to those of the protagonists of romantic Tang tales who, in their freely elected relationships, most often seem to luckily escape the dangerous twists and turns of fate, but sometimes are straightforwardly led to mental ruin or death. The best-known examples are “The Story of Huo Xiaoyu” (Huo Xiaoyu zhuan 霍小玉傳) and “The Story of Yingying” (Yingying zhuan 鶯鶯傳). To kill or die for someone, or to be a star-crossed lover, both mean sacrificing one's life for a transcendent goal. As in the Shiji account of Zhuan Zhu 專諸, who murders his ruler on the order of the ruler's son and sacrifices himself for the future prestige and prosperity of his own children, who are likely to be promoted to high positions by their father's sponsor, the virtue of the assassin-retainer lies in making himself indispensable for his master the very moment the master faces the obstinate resistance of social norms against his own will. It is merely in the mutuality of this master-client relationship ( $z h u$ 主 $-k e$ 客) that self-interest and selfless love outweigh each other, and thus this apparently egoistic bond becomes comparable to that of an erotic relationship on a give-and-take-basis and, potentially, may result in family fortune. Thus, the virtue of the assassin, which lies in his personal staunchness rather than in his "moral" nature, nevertheless stems from a reciprocal relationship as an elementary precondition of morality. It is for this reason in Sima Qian's account that the assassin Yu Rang 豫讓, after his last master - who had esteemed him more than any of his previous sponsors - is defeated and killed and his corpse abased by the victor, exclaims: "As the knight-errant dies for the one who knows him so the woman presents the one who takes delight in her with her beauty!" (Shi wei zhi ji zhe si, nü wei yue ji zhe rong 士為知已者死, 女為說己者容). ${ }^{3}$ Whereas beauty is seen as a sacrifice to sustain a heterosexual erotic relationship, death is not feared by those engaged in platonic love (between men). The 'transcendent goal' in both types of erotic relationships is, of course, not extramundane in the sense of classical metaphysics but in the sense of the otherness or strangeness ( $q i$ 奇) of the beloved one. Thus, in the perception of Tang-era cosmopolitans educated in the letters, lovers who have chosen each other may have had something in common with assassins.

Owen hints at this commonality in his 1996 essay, in which he insinuates that the paradigm of romance calls for variations: "Balances of free choice and compulsion play an important role in romance narrative, as they do in all Mid-Tang attempts to represent spheres of autonomy" (Owen 1996: 134). Theorizing about autonomy makes the story of Nie Yinniang comparable to other Tang-era fictional romances, which have thus far attracted much more critical attention. Nie Yinniang's fate, like the fates of the protagonists in the two romance stories mentioned above, unfolds in a succession of almost coincidental events; however, unlike the emotionally overwhelmed, rakish lovers of Cui Yingying or Huo Xiaoyu, this heroine autonomously - and therefore unexpectedly avails herself of each possibility to go around another bend on a winding path that will eventually take her into the realm of mountain-wandering, cloud-soaring immortals, which is the utopian Daoist vision of ultimate freedom. In Tang chuanqi, this realm is

3 Han Zhaoqi 2008: 3582. Christopher Lupke has made similar observations previous to my own. See Lupke 2016: 217. 
located beyond the limits of a world that incessantly ruins itself, as demonstrated by the fate of Nie's former lord's son who, in the final episode of the story, proves unable to realize her warnings.

Likewise, Yuan Jiao's Hong Xian ultimately escapes from a banquet (the social world) under the pretext of being drunk (having transcended social obligations) and leaves behind the disruptions she appeared to have overcome by her previous selfless intervention in what seemed an unfolding scenario of just another disastrous game of political intrigue. The two female assassins make their ultimate decisions autonomously, following an imperative free of any desire for personal gain that would hold them down in the human realm. Ascending to immortality for both means to become impersonal.

\section{Distance, silence, and slowness}

The narrative laconism of the literary text obviously defies any temptation of the author to spoon-feed his audience. This feature lends to Nie Yinniang's story a transparency I do not hesitate to call magic and which as such is splendidly recaptured in Hou Hsiao-hsien's adaptation. Unlike Hou's heroine, the Nie Yinniang of Pei Xing's story does not demonstrate any "difficulty communicating verbally and communing with others" (according to one critic, such behaviour might otherwise indicate Asperger's syndrome; Lupke 2016: 220). Like all typical chuanqi characters, however, she remains frugal in her use of speech but can express herself straightforwardly and without hesitation when she is compelled to make crucial decisions. These features of the protagonist strike the reader of the Tang tale in a similar manner as the silence that accompanies and creates distance from action sequences in the film captivates the spectator. This silence deliberately slows down the film's pace of action. The first scene establishes a certain dynamic to action sequences that sees energetic movement transform into wind. Nie Yinniang, tasked with assassinating a military commander, leaps out of a roadside thicket, slicing her victim's throat. He slumps down on his horse before falling into the grass; this movement is immediately converted into the swoosh of a breeze rustling through tall willow trees. From this very first moment of the picture, wind is a peregrine companion of human action, blowing curtains and lush vegetation and flickering candlelight, but never interfering directly. This device is a cinematic adaptation of the poetic yuanfeng 遠 風, the “far-going wind", a metonym for changes/transformations (bianhua變化) that do not mingle with human purpose but follow upon and are borne by great shifts in timely conditions concocted somewhere far beyond the scope of human subjectivity. However, there seems to be a clear interconnection between this windborne distance and the slowness in the way that things come to pass and in the way the camera establishes distance, yet at the same time remains intimately involved in the dynamics of each shot. Several of the numerous visual motifs expressing the flow of $q i$ 氣 ("vital breath, atmospheric as well as organic') originate in lyrical poetry, such as lush foliage and blooming trees in the spring wind, or - more frequently in the film as a whole - transparent curtains wavering in the breeze, haze wafting at the shores of silent waters, and meadows withering in autumnal mountains. The transparent curtains wavering in the breeze (shulian 疏策) are particularly pronounced and owe their efficacy to the fact that the invisible moving power 
(of wind or qi) transcends the frame of the camera. As Victor Fan opines, this type of shot calls to mind "that the camera and the viewer are part and parcel of the general environment that we observe, and from which we see our own reflection" (Fan 2015). Later, we will discuss Fan's evaluation of The Assassin as a "mirror" and its spiritual function to “illuminate the heart” (zhaoliang xinling 照亮心靈).

\section{Two tales intertwined to make a new story}

For those not familiar with both chuanqi the filmmaker drew from, I shall now briefly summarize their plots and main characters before continuing to investigate critical structures and narrative paradigms of The Assassin that cannot be discovered and explained without picking up on allusions to these earlier works.

Pei Xing's story "Nie Yinniang" recounts the life of the daughter of historical figure Nie Feng 聶鋒, a general of the quasi-autonomous province of Weibo 魏博, whose leader at the time was Tian Jian 田季安 (781-812), grandson of the notorious Tian Chengsi 田 承嗣 (705-779), a former henchman of An Lushan 安祿山 (c. 703-757), whose rebellion and ephemeral Yan dynasty 燕朝 (756-762) convulsed the eighth-century Chinese world. At the time the story was taking shape - first as urban gossip and later in the written form authored by Pei Xing - it was well-known that Tian Chengsi, thanks to his wit and cruelty, had managed to maintain the autonomy that An Lushan once had granted him by paying lip service to the sovereignty of the Tang court after it had succeeded in gradually re-establishing its political power. Thus, Nie Yinniang's father, Nie Feng, was in the service of a ruling house that was sanctioned by the imperial court as a part of its system to "rule the tianxia 天下”, literally 'the All-under-Heaven', and whose claim of autonomy, especially concerning the right of hereditary rulership, remained challenged by continuing interventions from the imperial government.

However, the story presupposes this historical context and does not elaborate on its details. Not even Tian Jian is explicitly mentioned by name because the author strictly focuses on the figure of Nie Yinniang. The six-year-old Nie Yinniang is kidnapped on the threshold of her parents' house by a Buddhist nun, who five years later returns the girl to her home as an accomplished assassin. When Nie Yinniang reveals her fate to her worried parents, she gradually loses their trust and love. This ultimate loss of family intimacy must have embittered her even more. In recalling her years in the nun's custody, she tells her parents that she once failed to carry out an assassination that had been ordered by her mistress because she pitied the child her would-be victim held in his arms. The nun returns Nie Yinniang to her family due to her "humane failure". Under these circumstances, she decides to marry a young peddler, whose only skill is mirror polishing; when her father dies shortly thereafter, she becomes a retainer in the ruler's (Tian Jian's) household. However, when she is commissioned to assassinate Liu Changyi 劉昌裔 (752-813), a powerful military leader and at the time the loyal governor of a neighbouring province, she meets in her victim a man of superior spiritual power and, surprisingly, does not hesitate to switch loyalties. After Nie successfully uses her magic skills to overcome two assassins dispatched by Tian Jian to take revenge for her treachery, she and her husband continue life as Liu's retainers. Years later, Liu is appointed to a high government office 
in Chang'an, whereupon Nie decides to leave his service and - after gaining his consent to pay a maintainable rent to her husband - abandons the world of men in search of an “accomplished person" (zhiren 至人) in the mountains. As the story draws to an end, Liu suddenly dies and is buried in the capital. Nie is reported as having shown up at the burial among other guests. Then, more than a decade later, Liu's son, on his way over a mountain pass in Sichuan, meets Nie again. Nie, who already seems to have reached a stage of Daoist self-perfection (immortality) warns him to resign from office and presents him with drugs to avoid forthcoming calamities. He, however, ignores her warnings and, soon after, dies. The final remark assures the reader that, from then on, no one would ever again hear of Nie Yinniang.

Compared to Pei Xing's narrative laconism, the style of Yuan Jiao's “The Story of Hong Xian" differs significantly. Hong Xian initially appears as an extraordinarily talented maid, serving in the household of Xue Song 薛高 (d. 773), another former henchman of An Lushan, who had also returned under the dominion of the imperial court and become an enfeoffed military governor (jiedu shi 節度使) of the loyal province of Luzhou. In contrast to Nie Yinniang, Hong Xian's personality shows no signs of obstinacy and her personal fate is not exposed to the reader's eyes from the very beginning. Initially, Hong Xian appears only as an extraordinary female servant because she possesses qualities that one would not expect from a "simple maid" (qingyi 青衣), such as musical and intellectual skills as well as intuitive intelligence.

After introducing Hong Xian's character, Yuan Jiao makes an excursion into the political background of the age with its swaying imbalances of regional powers that the imperial court strove to manage by building and maintaining family networks between leading clans. Xue Song, a member of such a network, senses that his daughter's father-in-law, Tian Chengsi (the governor of quasi-autonomous Weibo), is planning to attack him. Hong Xian intuitively understands her master's distress, approaches him in an undisturbed moment and, upon gaining his confidence, reveals herself as an "unusual person" (yiren 異人), a term that implies the possession of supernatural powers. Thanks to her abilities, Hong Xian reaches Weibo the same night and finds Tian Chengsi asleep in his palace. But instead of kidnapping or killing him on the spot, as the reader might expect of her because upon her departure from Luzhou she was depicted dressed in the style of a professional assassin and armed with a dagger, she intuitively decides to steal a golden box lying on the floor next to his bed that contains the "Eight Characters" (bazi 八 字) and some jewellery. ${ }^{4}$ After having returned with her plunder to Luzhou, she reports everything to Song and in conclusion exclaims: "Feeling worried, I left; filled with joy, I return"5 (you wang xi huan 憂往喜還) (Wang Bijiang 2008: 261). Thus, she left for her mission full of distress because of the perfidious plot planned by Tian against Song, but eventually returned full of joy because in a crucial moment her intuition showed her the way to resolve the problem without bloodshed.

4 According to the translator of the story Cao Weiguo, the Eight Characters "indicated the year, month, day and hour of a person's birth, each consisting of a Heavenly Stem and one Earthly Branch". Compare Nienhauser 2010: 13, footnote 48. In fact, the information contained in the Eight Characters refers to the cosmological existence of a person. One who possesses this information might be able to foresee coming events, evaluate options and non-options, and, thus, interfere in the fate of the original owner, which explains Tian Chengsi's consternation.

5 Modified translation after Cao Weiguo, Nienhauser 2010: 15. 
Song understands his servant and orders a messenger to swiftly return the box to Weibo, an action that deeply moves the already desperate Tian Chengsi, who apologizes to Song in a letter sent back to Luzhou and immediately calls off his murderous plans. At this point of the story, Hong Xian appears as an unexpected saviour in a disastrous world. It seems, however, as if a single deed sufficed to complete her mission, and soon after the two neighbouring provinces reconcile, Hong Xian declares her intention to leave Song. To justify her decision, she reveals to Song her own fate, which is conditioned by her previous incarnation as a male healer. It turns out that her heroic deed was intended as repayment for sins she had committed in a previous life. Thus, she concludes that the time had come to "withdraw myself from the mundane world and rest my heart on that which transcends secular affairs" (Nienhauser 2010: 21). And so she does soon after in the midst of a farewell banquet that Song has arranged in loving respect for his former maid who had saved him and his like from the impending carnage that would have been the only logical outcome of the tensions produced by their own greed and vengefulness.

Hong Xian is a model of virtue and, in the way she carefully observes and approaches her master from her very inferior position in his household, even displays a certain handsomeness. In comparison, Nie Yinniang remains obstinate, brittle, even queer, from the beginning to the end, when she forgoes insisting on her warnings to the son of her beloved master Liu Changyi, leaving him to his ruin. Her behaviour can be explained by her characteristics, which are highly specific for the heroes of Tang tales. She resolutely fights the cruelty of a fate she alone can face, and, regardless of others, she pursues a path that is more complicated and certainly more individualistic than Hong Xian's exemplary road to salvation. I believe the discrepancies between the two stories have been meticulously explored and skilfully exploited by filmmaker Hou Hsiao-hsien and his scriptwriter Chu Tien-wen in an attempt to fuse them into a new character, the Nie Yinniang of The Assassin, which bridges the millennium between the crisis of the world of the Tang and ours.

\section{A critique of the historical narrative as political metaphor}

Hou and Chu intentionally complicated the storyline of The Assassin by interweaving many details from the two Tang tales that were briefly summarized and discussed above. Both take place in the same historical setting, during an epochal stalemate in the tense political power struggle between the imperial court in Chang'an and an autonomous ruler, the hereditary governor of Weibo province, which also involved several other provincial governors in the region, both loyal and autonomous. What many historians of the Chinese empire (and of modern Chinese national history) interpret as a political dilemma during the late eighth century and the first half of the ninth century was actually a textbook example of realpolitik. The imperial court and the hereditary house of the rulers of Weibo, the Tian clan, had entered into a contract of sorts that would enable both to save face, notwithstanding mutual intrigues instigated by either of the two sides to subtly optimize its own position. In fact, this historical balance of power can help 
reflect on current-day tensions emerging under the umbrella of the One-China policy (yige Zhongguo zhengce一個中國政策) in the contemporary context of regional and global politics.

Of the two literary texts, "The Story of Hong Xian" alone elaborates on the political complications in the aftermath of the An Lushan rebellion (755-763) by explicitly mentioning the imperial court's diplomatic efforts at building a system of diplomatic marriages between provincial clans, whose leaders, very often former supporters of An Lushan, could not be forced to abdicate their positions as quasi-hereditary rulers who had to be formally recognized by the imperial government. By resorting to kinship diplomacy, the court, however, palliated, rather than resolved, the problem of mutual rivalry and potential violence between the elite clans, and, as we have seen earlier, this state of affairs led to the vital problem faced by Hong Xian. Hong Xian's heroism is clearly displayed against the backdrop of turmoil between provincial powers and in the general context of gossip about intrigues, slander, and conspiracy among members of high society in the provinces and in the capital. ${ }^{6}$ Thus, aspects of Hong Xian that are absent from the literary version of Nie Yinniang, such as the charity Hong still bears from her former life as a healer and her pity for those who are willing to harm others, are fused into the character of Hou and Chu's Nie Yinniang, who, in face-to-face-situations, appears aloof, almost numb, but as an emotional subject remains deeply intertwined with the fate of the world she was born into. The historical imbalances of power that roiled relations between the imperial court and regional elites generated a culture of slander, intrigue, and assassination plots which produced an environment that can easily be compared with today's atmosphere of wariness bordering on anguish, as well as of latent cynicism, that dominates relations between the two political, and increasingly also cultural, rivals on both sides of the Taiwan Strait.

The Assassin is far from being a mere adaptation of the literary text whose Chinese title it borrows. Brian Hioe does not err in judging that The Assassin follows in a series of productions that, over the past fifteen years since Zhang Yimou's Hero, have sought to blur the boundaries between 'martial arts' film and art film (Hioe 2015). But Hioe clearly overemphasizes the importance of a film's use of political metaphor for helping it achieve art film status. Although Hioe's assumption may adequately apply to Zhang's Hero, the political agenda of the Pro-Unification Left is hard to distinguish in the metaphorical language of The Assassin. Unquestionably, however, imbalances of political power have a strong impact on the classical human dilemma embodied by Hou's main character. The allusive style and principles of selection applied by Hou in his references to both literary sources reveal a psychological dichotomy. It is rooted in the desire for love, which for both main characters, Hong Xian and Nie Yinniang, is a desire to become recognized by those who can appreciate them ( $z h i$ ji 知已), and by those to whom they belong, and a yearning for freedom of choice, which ultimately leads both of them to leave the human world.

6 The most recent and probably one of the most topical discussions of the problem of fictionality and narrativity in Tang chuanqi, which, in a way, contradicts the discussion about the legitimacy of reading a political metaphor in The Assassin, has been produced by Sarah M. Allan (2014); see especially chapter 2, "Filling the Gaps: Tales on and against History" on pages 0-118. 


\section{The historical backdrop and the main characters}

In the second half of the eighth century, An Lushan's rebellion had exhausted the country, decimated its population, sparked a dangerous migration of impoverished refugees, and destroyed mutual trust between the regional elites as well as between these elites and the imperial court. The mid-century rebellion created a moral vacuum in the minds of those who had survived civil war and experienced the ensuing disorder. These events can perhaps be legitimately compared with the series of brutal dictatorships East Asia and many other regions of the world suffered for several decades during and after World War II.

Military commanders were commissioned with upholding "standard rules" in the provinces and controlling potentially disloyal elements. Cruelty was often considered a practical, indispensable tool wielded by rulers to maintain order. But the arbitrary use of power had negative consequences, and to mitigate them the court sought to encourage marriages between imperial clan members and provincial elites as well as between the families of military governors or jiedush $i$ 節度使 (literally: 'those charged with upholding standard rules'). This method, it seems, led to greater success than that acknowledged in the mainstream historical narrative, which presents a political history of the Tang empire after the suppression of An Lushan's rebellion in which central power is in permanent decline. As a matter of fact, from the 820 s until 880 , an overwhelming majority of provincial governors were again directly appointed by the imperial government (Tackett 2014: figure 4.2). Therefore, in a recent study on the crisis of medieval Chinese aristocracy Nicolas Tackett suggests that 'the dynasty remained relatively stable until quite late in the 9th century' (Tackett 2014: 145). If we accept his view - which seems well grounded then the historical situation becomes even more interesting. Historians write about Hebei jiushi 河北舊事, or “Hebei-custom", ${ }^{2}$ with respect to the exceptional autonomous status of the three provinces located on the territory of present-day Hebei; here, the position of governor was inherited during practically the entire period beginning with the rebellion and ending with the final collapse of the dynasty. According to Tackett, none of the three clans ruling these de facto autonomous provinces had a history of sons having served as officials under the Tang and had almost no active ties with the empire's heart of power brokerage, the "capital marriage network". These autonomous lineages were founded by military leaders who had sided with An Lushan during the period of open civil war shortly after the mid-eighth century. As we have seen in "The Story of Hong Xian", Weibo's founding father, Tian Chengsi, in fact figures as the main character in an intermarriage network between the governors of autonomous and loyal provinces initiated by the court in a strategical attempt to appease the territories to the north and south of the lower Yellow River valley. With the exception of such periodical and more or less successful attempts to gain more influence via intermarriage, the central government's role in the politics of the region was often that of a mere bystander.

In the plot of The Assassin, the cinematic character of Princess Jiacheng (Jiacheng gongzhu 嘉誠公主), the mother of Tian Jian, and her twin sister in the film, the Daoist

The term goes back to Charles Allen Peterson's study “The Autonomy of the Northeastern Provinces in the Period Following the An Lu-shan Rebellion” (Peterson 1966). See Tackett 2016: 151. 
nun who educates Yin'niang and later orders her to assassinate Tian Jian, personify the schizophrenic political constellation, a theme that lurks under the surface of the narrative. In Christopher Lupke's words, Jiacheng

was the daughter of Emperor Daizong of the Tang (代宗; 727-779), and the princess's brother, Dezong 德宗 (742-805), betrothed her to Tian Xu [governor of Weibo to whom she bore Tian Jian] as a way of maintaining amity between Weibo and the central court. This becomes a crucial plot in the film because Princess Jiacheng is portrayed as a forlorn woman, living outside her own land with no one to share her culture, and she is extremely lonely (Lupke 2016: 221).

It is as if, in the meanwhile after her death, Princess Jiacheng's loneliness had spread among those closely related to the court of Weibo. During her first encounter with her returned daughter, Nie Yinniang's mother, Nie Tian shi 最田氏, gives her a broken jade ring and explains its meaning as a symbol of rupture between Princess Jiacheng and her own imperial family, which had sent her to Weibo to improve relations with the court. Soon after the princess's arrival, Nie Tian shi continues, she sent her imperial entourage back to the capital and decided to stay alone as the wife of the governor of Weibo. "From that moment on", she tells her daughter with a sigh, "the court was the court, and Weibo was Weibo". After the ultimate severance of the princess from her imperial family, the princess devoted her life to her son and husband. But she had already sacrificed what must be seen as her free will because the rupture had been forced upon her by the contradicting political interests of others, and her personal decision to stay loyal to her husband reflects her lack of interest in becoming involved in political machinations. Thus, Nie continues to tell her returned daughter the story of the

Blue Bird Dancing in Front of a Mirror, in which a blue bird is caged by a king - a parable of her [Princess Jiacheng's] own entrapment. The bird refuses to sing for three years, when one day the king offers her a mirror and asks her to dance. Upon seeing her own image, she lets out one last cry and dies. The reflection that the blue bird sees is her incarcerated self, and she dies in her state of imprisonment (Fan 2015).

In this central parable the entanglement of love, freedom, and death on a human level is apparent. It is the core of the aesthetic and psychological dynamics that form human relations in the film and urge Nie Yinniang to make the decisions that free her from being governed by the interests of others.

After Jiacheng's death and during the concrete time period covered by the plot of The Assassin, political affairs in Weibo became even more complicated. In one scene Tian Jian, confronted with the imperial government's policy of pinpricks, listens to his advisors in his palace's audience hall, but soon proves unable to bear their debate on whether to take a more affirmative stance or to try to actively avoid getting roped into a military confrontation provoked by the imperial court. ${ }^{8}$ It is not clear which adviser's doctrine

8 This depiction of Tian Jian's behaviour and character is by and large congruent with the way he is portrayed as a cruel ruler who lacks self-control in Universal Mirror of Governance (Zizhi tongjian 資 治通鑑, juan 238) by Sima Guang 司馬光 (1019-1086). 
enrages him most. He seems overburdened with his responsibility as a ruler. Hardly understanding himself anymore, he grows angry.

This scene makes the most obvious allusion to contemporary cross-strait relations. It is hard to imagine that a viewer familiar to any degree with the official and unofficial political discourse on the legitimacy of the de facto independent state of the Republic of China would miss the parallel while listening to one of the disputing advisers explain that violent action from the side of the Tang court to overthrow Weibo, despite successful precedents elsewhere, could only fail "because the ruler and government of Weibo enjoy the trust and full support of the population".

This is one - and in my understanding the only - spot in the film where contemporary political problems shine through the dense historical texture of the plot in a scene that seems to reflect a historical situation. This narrative ambiguity bears some resemblance to the traditional literary technique of "satirizing the present by referring to the past" ( $y$ i gu feng jin 以古諷今). It is worth noting that Tian Jian's eruption only silences the advisors but does not seem to entail resolute action.

\section{Nie Yinniang and Hong Xian}

What kind of woman is Nie Yinniang? Hou's character outwardly differs from all other female characters in the film. Tian Jian's wife in the film, Tian Yuan shi 田元氏, calls her the 'black female knight-errant' (hei nüshi 黑女士) and later appears as a knight-errant herself, but whether she does so to protect her own children (and the state?) or to satisfy her jealousy remains unclear. Nie's outfit flouts the court fashion of lush, coloured robes, her sparingly adorned hairstyle differs radically from the "cloud-style" fashionable in the milieu of Tang-dynasty high society, and - in stark contrast to the meticulous work that was spent on every historical detail of dress and furniture as well as on aspects of language and gesture - her slim body bears not even the slightest resemblance to the Tang concept of female beauty. According to van Gulik, the men of the era "liked sturdy women, with round, chubby faces, well-developed breasts, slender waists but heavy hips" (Gulik 2003: 188). The authors of Tang tales preferred a kind of aristocratic or exotic beauty that Nie Yinniang obviously lacks; likewise the audience of such stories enjoyed gossiping about the power this beauty could have on effeminate young men, who lusted after such women. Nie, veiled in a black garment whose darkness blends into that of her glossy long hair, carries herself with an unwavering bearing that expresses enigmatic, unyielding resolution; therefore, she could almost be interpreted as a female counterpart of the popular "fragile scholar", whose bodily appearance "with his narrow shoulders, frail physique, slim waist, and tender gesture, is highly feminized” (Geng 2004: 69). This makes the main figure of The Assassin appear even stranger in the eyes of the spectator who bears in mind the stereotypical gender roles of Tang chuanqi narration.

By referencing Foucault's Discipline and Punish, Song Geng in her study The Fragile Scholar: Power and Masculinity in Chinese Culture

reveals the body as an object of knowledge and as a target for the exercise of power. "The body is shown to be located in a political field, invested with power relations which render 
it docile and productive, and thus politically and economically useful... a body is docile that may be subjected, used, transformed and improved." This procedure of training or coercing bodies is done through the technique of power termed 'discipline' by him [Foucault]. The political technology of the body thus links power relations, knowledge and the body (Geng 2004: 69-71).

In this sense, Nie Yinniang's body is almost overdisciplined. During her years as the nun's apprentice, a time when she reached sexual maturity, she remained isolated from society, with the exception of a few other girls who were also trained by the nun. Thus emancipated from social and political power relations between the sexes, she is trained to kill smoothly and without leaving traces. But the fraud inherent in this independence from social and gender hierarchies can be observed at the very beginning of the film, when Nie is presented as the "docile and productive" instrument of her nun-mistress, a hidden player in a major power game. In fact, she appears trapped in her disciplined and invincible body, and the story Hou tells is one of growing subversive hesitation in playing the role assigned to her. Employing this practice of hesitation helps her ultimately succeed in undermining the "political technology of the body", allowing her to proceed on her heroic path to freedom obtained through her personal strategy of non-action (wuwei 無為). ${ }^{9}$

Now, let us return to Nie's antagonist, female assassin Tian Yuan shi, who was mentioned briefly at the beginning of this section. It is important to note that her true identity, the zealous wife of Tian Jian and a mother determined to defend her children, whom she probably deems threatened by Nie Yinniang's incursions into the palace, can only be revealed by the viewer by decoding her facial expressions hidden behind a mask. In her first scene, she appears alone in the palace park, pacing back and forth in search of her antagonist and holding a long, curved dagger (Nie's only weapon is an almost invisibly short knife) without uttering a single word. Her purple robe differs starkly from Nie's black garment, and in several other details, her outfit recalls the description of Hong Xian as she prepares herself for setting out on her mission: "She combed her hair into a wuman 烏蠻 bun, ${ }^{10}$ clasped with a golden phoenix hairpin, dressed herself in short robe with purple embroider, tied on a pair of light shoes with green silk ribbons, strapped a dragon-patterned dagger around her breast, wrote the name of the God of the Grand One on her forehead." 11 Hong Xian is talented and well educated, serving her patron, a governor, in offices that would have been the privilege of male aspirants. Later, sexual ambiguity turns out to be part of her identity as she declares herself the female reincarnation of a learned healer who had inadvertently killed a pregnant woman and two male embryos in an attempt to cure the would-be mother. Thus, her existence as a mean female servant is explained as a form of atonement for a sin committed in a former life;

9 The crucial function of this hesitation/non-action in the plot may be the, or at the very least, one reason why "Hou and company changed the Buddhist nun from the original Tang text to a Daoist priestess in the film version" (see Lupke 2016: chapter 6, endnote 11, 228).

10 Translator's note: "Wuman was a minority nation which lived in the south-west of Tang China. The 'wuman' bun is to comb one's hair into a high bun on the top of the head.' (See Nienhauser 2010: 10, footnote 38.) This description seems, at least in part, to coincide with the hairstyle Yuan Tian Shi wears as an assassin in the film.

11 Tr. Cao Weiguo (Nienhauser 2010: 10). 
her former vow as a healer to "save the world from calamities" (qiu shiren zaihuan 救世 人災患) also accounts for her eagerness to protect and save her patron from misfortune and to prevent the greater calamities that might be caused by unleashing the political conflicts looming over him. The complex nature of Hong Xian's motives is obviously echoed in the character of Tian Yuan shi as a female assassin, because her jealousy as a wife must be intertwined in some way with remorsefulness - she had been placed at Tian Jian's side despite his engagement to Nie Yinniang - and at the same time with concern for the future of the state and its de facto ruling house whose patriarch has come under direct threat.

Both characters, Nie and Hong, clearly differ from the archetypical femme fatale famous from Tang chuanqi; Hong, however, bears certain traits of an alternative literary archetype, the female beauty in caizi-jiaren 才子佳人 (scholar-beauty) ${ }^{12}$ tales, best represented by Lady Li ( $\mathrm{Li} \mathrm{Wa}$ 李娃) in Bo Xingjian's influential story. Not unlike Lady $\mathrm{Li}$, Hong does great things by serving her male counterpart in a most unselfish manner. However, the relationship between Hong Xian and her patron is not romantic. She is initially a simple servant before disclosing her magic powers, with which she offers to help her patron who has found himself in great trouble. In the end, she forsakes her patron's offer to stay in his household and departs under false pretences from her farewell banquet. Hou's Nie Yinniang has even less in common with Hong Xian than the original literary character in Pei Xing's tale. Nevertheless, in a psychological reading of the plot, Tian Yuan shi, bearing several of Hong Xian's traits, appears to be the protagonist's alter ego. Thus, the climax of the film occurs when the two women, both emotionally attached to Tian Jian, meet as two assassins in a birch grove. They seem to have used telepathy to find each other and do not exchange a single word before, during, or after the fight. Clearly, Tian Yuan shi is the one who seeks confrontation first, by exceeding the limitations imposed on her by her social roles of the heir apparent's mother and the ruler's wife. During the duel, she lashes out several times against her adversary until the latter, in a counterattack barely perceptible on screen, slashes Yuan's golden mask. An alter ego once unmasked loses the hidden power provided by a facial covering. After the fight, these two similar characters separate, each walking her own way out of the grove.

\section{Successive decisions}

In Pei Xing's tale, Nie Yinniang seems particularly apt to make decisions completely on her own. In this story, five life-changing decisions are made; the first, the Buddhist nun's decision to kidnap the girl, and the third, the Weibo ruler's (Tian Jian's) half-hearted decision to take Nie Yinniang, of whose skills he has only the faintest idea, together with her husband into his household after the death of her father, were not her own. Initially, her hesitance to kill cannot be properly described as her decision, but rather as her inability to obey the order of a person who had stolen her childhood to destroy the life of another innocent person. This idea remains unspoken in the literary tale, but the film

12 For a more detailed investigation into this literary genre from a gender- and body-culture studies perspective, see Geng 2004, which focuses on romance fiction. 
explicitly demonstrates that Nie is aware of the fact that another person had stolen the right of her parents and, thus, disrupted her development by depicting her return to her former master in the mountains for a final farewell before travelling back to a place of her personal choice to re-establish the autonomy she lost the moment it had been taken from her parents. (In the Tang tale it is on the contrary in the mountains where she departs from the human world to join the realm of immortals). However, in the eyes of some critics, Hou's Nie, by ultimately returning to that ulterior and perhaps utopian land at the other end of the tunnel, practices "aesthetic escapism". ${ }^{13}$ I disagree with this widespread understanding; this misjudgement resonates with the wholesale neglect of classical, premodern literary aesthetics due to the domination of twentieth-century ideological stereotypes. Instead, we should consider the act of “returning” ( $g u i$ 歸) to a place that opposes the hitherto experience of reality as a poetic gesture of making one's own, free choice, to which the plot ultimately amounts. This gesture is the quintessence of Nie's rigid engagement with a social and political environment whose logic of violence has exploited her.

The second decision in the Tang tale, the first one she makes alone, comes as a surprise to everyone except herself. One day, a peddler appears at the same door where several years before the Buddhist nun had begged for alms. He is young and unsuspecting, and $\mathrm{Nie}$, in open violation of protocol, declares her will to marry him: "This one may become my husband” (ci ren ke yu wo wei fu 此人可與我為夫) (Wang Bijiang 2008: 271). She shows no passion at all for the man, and at first it seems she merely sees in him an opportunity to change her primary social status because she feels her parents have lost true affection for her. On the other hand, she responds so rapidly that she obviously does not have the time for deliberation and instead of acting on careful calculation, she acts on intuition. This time her queerness happens to be in accordance with the resigned mood of her father, who only fears the murderous skills of his daughter and is relieved to get her out of the house. Soon after this turning point in her life, her father dies, and she and her husband continue their existence under the custody of Tian Jian (whom the tale does not mention by name).

The fourth decision is made a few years later, when Tian experiences trouble with the chief of a neighbouring commandry, one that maintains closer relations with the court, and decides to send Nie Yinniang and her husband to assassinate his rival. On their arrival at the gate of their declared victim's residence, Nie Yinniang again intuitively perceives his extraordinary skills and his sympathetic nature, which in her mind may substitute for the family intimacy she had lost years ago: "Vice-chancellor Liu must be a genius. If he would not be one, how could he have recognized me?!” (劉僕射果神人, 不然者, 何以 洞吾也). At first Liu resolutely rejects this idea: “This must not be. Each loves his patron; this is a common human thing!" But Nie Yinniang knows more than "common human things", and Liu ultimately accepts her statement.

Her final decision comes after her new, self-chosen patron Liu has been appointed to an office at the imperial court. Given the fact that she had voluntarily chosen to abandon her previous patron, the quasi-ruler of autonomous Weibo, in favour of the governor of a loyal province whom she subsequently defends against attempts from Weibo to take revenge, her indifference about her master's promotion is rather unexpected as was her

13 See Hioe 2015: "Conclusion: A Flight from Politics into Aesthetics." 
resolution a few years earlier to change social affiliation without being authorized. Also, her implicit decision to "delve into mountains and waters in search of an accomplished person, however, not without asking for a bit of a pension for her husband" (zi ci xun shan shui, fang zhiren, dan qi yi xu gei yu qi fu 自此寻山水, 訪至人, 但乞一虛給與其 夫) contravenes the rules. She also does not seem inclined to discuss the decision with her husband. At this point in the tale, however, Pei Xing adapts his Nie Yinniang to the literary scheme of the Daoist hero who seeks to leave the world. With her last, stunning decision, she has fulfilled her mission in the literary cosmos produced by Tang culture and can leave the stage to become an impersonal hero of immortality (Daoist transcendent freedom).

It must be acknowledged, however, that the main character's line of action is motivated by two mutually engaged factors: disillusioned self-awareness and a strong intuition, which together trigger a sense of personal liberty that was unheard of among the standard values of Tang society. The Nie Yinniang of the tale is depicted as a subject who gradually gains control over fateful decisions until she can make them independently. With the last of her decisions - not to accompany Liu Changyi to the capital, but to forsake all social bonds, including wedlock, and to "go into the mountains" ( ru shan 入山) - she personally stands up to and rejects imperial (and society's) power over her own body, liberating herself and achieving the impersonal freedom Tang society's spiritual culture seems to have valued so much higher than moral purity or righteous conduct.

\section{This-worldliness and freedom}

Both tales that have been reworked and merged to create the film's screenplay end with the literary trope of escaping from the world of the narrative into a spiritual void; the film, however, at least as I perceive, does not. Recalling Hioe's quite assertive suspicion that "The Assassin may be Hou's attempt to flee into an aesthetic wonderland as a way of avoiding confronting political reality" (Hioe 2015), I feel it now appropriate to address the fact that in the film Nie Yinniang never really escapes the dilemma of her cruel fate. She does, however, seem to avoid being consumed by it.

At first sight Hou seems to completely ignore Nie Yinniang's husband in the tale, a “young mirror polisher” (mojing shaonian 磨鏡少年). The film, however, features a young man, who first appears along the roadside amid the carnage of a fight between soldiers from Weibo and their adversaries. At this very moment, it seems Nie's father, Weibo general Nie Feng, is posed to die as yet another victim of the political hazards all protagonists are equally exposed to. Barely armed with a wooden pole, the youngster courageously jumps into the fray and manages to protect the general before Nie Yinniang suddenly arrives to turn the tide. Then, this company of three continues travelling through landscapes both lush and desolate until they pass through a long cave reminiscent of the one which in Tao Qian's (365-417) utopia "Peach-blossom Spring" (Taohuayuan $j i$ 桃花源記) leads from a world dominated by dynasties, officials, and history to a realm free from all such matters. After the group arrives in a village somewhere inside this new landscape, whose grand mountains and valleys remain unstained with the gaudy colours of flying banners, robes of travelling entourages, or sophisticated architecture, 
the young lad sits down among the peasants to polish mirrors and to amuse the locals. In an illuminating reading of this scene, Victor Fan interprets The Assassin as conveying an ideal central to Zen (or in Chinese, Chan) Buddhism: mingxin jianxing 明心見性, 'illuminate the heart', thus allowing nature to reveal itself:

... The film cuts to a long shot of the mirror polisher demonstrating his work to a group of children. After he removes the dirt from the surface of a mirror, the children see their reflection. Contrary to the blue bird, which lets out her last cry upon seeing her state of incarceration, the children see in the mirror nature that illuminates from within themselves. In this sense, Yinniang and the mirror polisher are not forming a romantic relationship; rather, they are letting go of all relationships, setting themselves free from human troubles and sufferings (Fan 2015).

Inconsistent with Fan's assumption that Nie Yinniang and the mirror polisher in Hou's film reject forming a relationship in order to transcend human suffering is Nie's intense, passionate quest for freedom, not in a metaphysical, but rather in an individual sense. Compared to her counterpart in the Tang tale, her proper character is modern because she does not need to get married to the mirror polisher in order to obtain a new, if only intermediate social status as a wife, nor does she seek out a better patron whose personality is more worthy of her own talent. These moves within the social texture of traditional Tang society are absent from the plot of the film. Hou's Nie Yinniang approaches her fate - the cruelty of which is equal to the cruelty of her own, highly professionalized art of assassination - from an angle of radical worldliness. Her stalwart hesitance to carry out the assassinations she has been tasked with means a rejection of the impersonal cruelty that eliminated her childhood and the emancipation of her individual humanity from what her nun-mistress ultimately calls the "Way of the Sword" (jiandao 劍道), or as I call it the prerogative of violence in a world of swaying imbalances of power. Gradually liberating her body from the impertinence of being "politically useful" in others' interests, she reveals an unfaltering desire to cut her own path through a world whose fate is as unpredictable as the winds that pervade its landscapes. Ultimately, it is this unpredictability which like a mirror reflects free will as the unconditional property of the individual.

\section{Conclusion}

Christopher Lupke has called The Assassin a "beautiful rendering of a classic, even clichéd, topic", "a story of tragic love undermined by politics", and "an excursion into the complicated details of internecine historical conflict in premodern China” (Lupke 2016: 224). To his assessment I would add the main insight I gained from my attempt of a close reading of some of the main structural elements of this cinematic work. Hou Hsiao-hsien and Chu Tien-wen's reinvention of Nie Yinniang and Hong Xian in the main character of The Assassin (named Nie Yinniang) implies a subtle reading of the historical context of those two unusual Tang chuanqi as metaphors for imbalances of political power and their impact on individual freedom in a contemporary - and perhaps even universal - sense. Watching the hero disappear in the autumnal meadows of a wide valley, followed only 
by companions of her personal choice, makes one think of Mill's equally timeless and laconic definition of individual freedom: "The only freedom which deserves the name, is that of pursuing our own good in our own way." 14

\section{REFERENCES}

Allan, Sarah M. (2014). Shifting Stories. History, Gossip and Lore in Narratives From Tang Dynasty China. Cambridge, Mass.: Harvard University Press.

Alternburger, Roland (2009). The Sword or the Needle: The Female Knight-Errant (xia) in Traditional Chinese Narrative. Bern, New York: Peter Lang.

Berlin, Isaiah (1969): “Two Concepts of Liberty." In: Isaiah Berlin, Four Essays on Liberty. Oxford: Oxford University Press.

Chang Hsiao-hung (2007): "The Unbearable Lightness of Globalization: On the Transnational Flight of Wuxia Film." In: Darrell William Davis and Ru-shou Robert Chen (edd.), Cinema Taiwan. Politics, popularity and state of the art. London: Routledge, 95-107.

Fan, Victor (2015). "The Something of Nothing. Hou Hsia-hsien's The Assassin" [on-line]. Los Angelos Review of Books. Accessible at https://lareviewofbooks.org/article/the-something-of-nothing-hou -hsiao-hsiens-the-assassin/ (accessed 19-09-2017).

Geng Song (2004). The Fragile Scholar. Power and Masculinity in Chinese Culture. Hong Kong: Hong Kong University Press.

Gulik, Robert H. van (2002). Sexual Life in Ancient China. A Preliminary Survey of Chinese Sex and Society from ca. 1500 B.C. Till 1644 A.D. Leyden: Brill.

Han Zhaoqi 韓兆琦 (2008). Xinyi Shiji VI: liezhuan 新譯史記 (六) 列傳 []. Taibei: Sanmin shuju.

Hioe, Brian (2015). "Hou Hsiao-hsien's The Assassin and the Pro-Unification Left" [online]. New Bloom 2015. Accessible at https://newbloommag.net/2015/11/28/the-assassin-pro-unification-left/ (accessed 19-09-2017).

Lupke, Christopher (2016). The Sinophone Cinema of Hou Hsiao-hsien. Amherst. (NY): Cambria Press.

Nienhauser, William H., Jr. et al. (edd.) (1986). The Indiana Companion to Traditional Chinese Literature. Bloomington: Indiana University Press.

Nienhauser, William H. (2010). Tang Dynasty Tales. A Guided Reader. Singapore: World Scientific.

Owen, Stephen (1996). The End of The Chinese Middle-Ages. Essays on Mid-Tang Literary Culture. Stanford (Calif.): Stanford University Press.

Tackett, Nicolas (2014). The Destruction of the Medieval Chinese Aristocracy. Cambridge (Mass.): Harvard University Press.

Tsu, Jing (2008). "Female Assassins, Civilization, And Technology in Late Qing Literature and Culture." In: Qian Nanxiu, Grace S. Fong et al. (edd.), Different Worlds of Discourse. Transformations of Gender and Genre in Late Qing and Early Republican China. Leiden: Brill.

Wang Bijiang 汪辟㽬 (ed.) (2008). Tangren chuanqi xiaoshuo 唐人傳奇小說 [Chuanqi Tales by Tang Authors]. Taibei: Sanmin shuju.

14 J. S. Mill, “On Liberty”, quoted after Berlin 1969: 3. 